\title{
NEW DISTORTION THEOREMS FOR SAKAGUCHI FUNCTIONS
}

\author{
M. ÇAĞLAR AND Y. POLATOĞLU
}

Abstract. Let $A$ be the class of functions $f(z)$ of the form $f(z)=z+\sum_{k=2}^{\infty} a_{k} z^{k}$ that are analytic in the open unit disk $\mathbb{D}=\{z \in \mathbb{C}|| z \mid<1\}$. In 1959, K. Sakaguchi [9] has considered the subclass of $A$ consisting of those $f(z)$ which satisfy $\operatorname{Re}\left(\frac{z f^{\prime}(z)}{f(z)-f(-z)}\right)>0$, where $z \in \mathbb{D}$. We call such a function a "Sakaguchi function", and denote the class of those functions by $S_{S}$. Various authors have studied this class $([6,7,9,10])$. We obtain new distortion theorems, Koebe domain, k-quasiconformality, and the radius of convexity for the class $S_{S}$.

Mathematics subject classification (2000): 30C45.

Key words and phrases: Sakaguchi function, starlike function, Koebe domain, $k$-quasiconformality.

\section{REFERENCES}

[1] S. D. BERNARDI, New distortion theorem for functions of positive real part and applications to the partial sums of univalent convex functions, Proc. Amer. Math. Soc., 1, (1974), 113-118.

[2] C. CARATHÉODORY, Untersuchungen über die konformen Abbildungen von festen und veränderlichen Gebieten, Math. Ann., 72, (1912), 107-144.

[3] F. W. GeHRING, Characteristic Properties of Quasidisks, Les Presses de l'Université de Montréal, 1982.

[4] A. W. Goodman, Univalent Functions, Vol. I, Mariner Publishing Company Inc., 1983.

[5] I. S. JACK, Functions starlike and convex of order $\alpha$, J. London Math. Soc., 3, (2) (1971), 469-474.

[6] S. OwA, Geometric and Univalent Function Theory Seminar Notes, İstanbul Kültür University Press, İstanbul, 2006.

[7] V. RAVICHANDRAN, Starlike and convex functions with respect to conjugate points, Acta Mathematica Academiae Peadagogica Nyıregyhaziensis, 20, (2004), 31-37.

[8] M. S. RoberTson, On the theory of univalent functions, Ann. Math., 37, (2) (1936), 374-408.

[9] K. SAKAGUCHI, On a certain univalent mapping, J. Math. Soc. Japan, 11, (1959), 72-75.

[10] J. SoKOL, Functions starlike with respect to conjugate points, Zeszyty Nauk. Politech. Rzeszowskiej Mat. Fiz., 12, (1991), 53-64. 